Bond University

Research Repository

\title{
Skeletal Muscle Mass and Fat Mass Relationships With Physical Fitness Test Performance in Law Enforcement Recruits Before Academy
}

Lockie, Robert G.; Carlock, Blake; Ruvalcaba, Tomas J; Dulla, Joe; Orr, Rob Marc; Jay Dawes, J.; McGuire, Megan

Published in:

Journal of Strength and Conditioning Research

DOI:

10.1519/JSC.0000000000003918

Licence:

Other

Link to output in Bond University research repository.

Recommended citation(APA):

Lockie, R. G., Carlock, B., Ruvalcaba, T. J., Dulla, J., Orr, R. M., Jay Dawes, J., \& McGuire, M. (2021). Skeletal Muscle Mass and Fat Mass Relationships With Physical Fitness Test Performance in Law Enforcement Recruits Before Academy. Journal of Strength and Conditioning Research, 35(5), 1287-1295.

https://doi.org/10.1519/JSC.0000000000003918

\section{General rights}

Copyright and moral rights for the publications made accessible in the public portal are retained by the authors and/or other copyright owners and it is a condition of accessing publications that users recognise and abide by the legal requirements associated with these rights.

For more information, or if you believe that this document breaches copyright, please contact the Bond University research repository coordinator. 
Skeletal Muscle Mass and Fat Mass Relationships with Physical Fitness Test Performance in Law Enforcement Recruits before Academy 


\section{Abstract}

The purpose of this study was to analyze relationships between skeletal muscle mass percentage (SMM\%) and fat mass percentage (FM\%) relative to fitness test performance in law enforcement recruits. Retrospective analysis was conducted on 338 recruits (271 males, 67 females) from four academy classes. SMM\% and FM\% were measured using cost-effective and practical bioelectrical impedance analysis (BIA) equipment that used hand and foot placement. The fitness tests included: grip strength; vertical jump; 75-yard pursuit run; 2-kg medicine ball throw (MBT); push-ups and sit-ups completed in $60 \mathrm{~s}$; and the 20-m multistage fitness test. Partial correlations controlling for sex derived relationships between SMM\%, FM\%, and the tests. Recruits were split into quartile groups for SMM\% and FM\% (Group 1 had the lowest SMM\% or highest FM\%; Group 4 the highest SMM\% or lowest FM\%). A one-way MANOVA, with sex as a covariate and Bonferroni post hoc, compared between-group results. SMM\% correlated with all fitness tests expect for MBT; FM\% with all but grip strength and MBT $(r= \pm 0.107-0.293)$. Greater SMM\% or lesser FM\% tended to relate to better fitness test performance. The MANOVA data indicated Groups 3 and 4 (better SMM\% or FM\% profiles) exhibited superior fitness than Group 1 (poorest SMM\% or FM\% profile) $(p \leq 0.048)$. Recruits should ideally increase SMM\% and decrease FM\% before academy to optimize fitness training and testing performance, although specific guidelines should be agency-specific. Staff could use BIA to monitor body composition during academy to indicate how recruits are tolerating training.

Key words: bioelectrical impedance analysis; body composition; deputy sheriff; police; tactical 


\section{INTRODUCTION}

Law enforcement can be a physically challenging profession, and officers need to perform tasks such as rescuing civilians or partners, vaulting obstacles, administering defensive tactics, and pursuing and apprehending suspects $(25,33)$. As a result of these demands, law enforcement recruits complete academy training before they become sworn officers $(10,25,27,34)$. Physical training is an important component of academy training and is administered by law enforcement agency (LEA) staff. Common training approaches during academy for recruits includes metabolic conditioning (e.g. continuous and interval running), and resistance training (10,34). In addition to fitness improvements $(10,34)$, another positive outcome that could result from physical training are favorable changes in body composition. Correct implementation of certain training methods could increase skeletal muscle mass (SMM) (40) and decrease fat mass (FM) (10). However, there has been minimal analysis of body composition of law enforcement recruits prior to academy training.

There has been some analysis of body composition in other law enforcement populations relative to physically demanding tasks. Violanti et al. (42) analyzed the association between BF percentage $(\mathrm{BF} \%)$ estimated from skinfolds measured from three locations (chest, abdomen, and thigh for men; triceps, suprailium, and thigh for women) and fitness test performance in incumbent police officers. A lower BF\% was generally associated with more push-ups and sit-ups completed in $60 \mathrm{~s}$, better sit-and-reach test performance, and faster $2.4-\mathrm{km}$ run times in male officers. For the female officers, lower BF\% was linked to more sit-up repetitions and a faster 2.4-km run time. Dawes et al. (13) used the same skinfold measures to estimate BF\%, FM, and SMM in incumbent male officers, and determined relationships with different fitness tests. The results demonstrated that greater SMM was related to more push-ups completed in $60 \mathrm{~s}(r=0.444)$, a greater one- 
repetition maximum bench press $(r=0.781)$, and a higher vertical jump (VJ; $r=0.391)$. In contrast, greater BF\% related to fewer push-ups in $60 \mathrm{~s}(r=-0.413)$ and a lesser VJ $(r=-0.566)$. More FM correlated with a lesser VJ ( $r=-0.369)$ and slower 2.4-km run time $(r=0.399)$. Dawes et al. (12) found similar results in Special Weapons and Tactics officers. Less FM was associated with more push-ups and sit-ups completed in $60 \mathrm{~s}$, and pull-ups, and a faster completion time on a job-specific obstacle course.

Although this may be expected, there are potentially other impacts of body composition on law enforcement recruits. Several of the tests analyzed by Violanti et al. (42) and Dawes et al. $(12,13)$ are also used as training modalities during physical training for law enforcement academies. This includes push-ups and sit-ups to develop muscular endurance and strength, jumping to develop power, and continuous running to develop aerobic capacity $(10,25,34)$. Law enforcement recruits with less SMM and more FM body composition may not perform well in training modalities used to develop these qualities. As there can be cumulative effects of poorer performance in muscular endurance and aerobic exercises (15), this is an issue. For the recruit with less SMM and/or more FM (or more non-functional mass), they more perform fewer muscular endurance or strength exercises, and will work at a higher intensity for given aerobic exercises. This could limit the fitness adaptations they could experience during academy, which is problematic as poorer fitness has also been linked with academy attrition $(15,27)$ and may increase injury risk (39). This could have a further downstream effect, as strength, power, muscular endurance, and aerobic capacity form the foundation of job-specific tasks for law enforcement officers $(3,25)$.

Additionally, there has also been some analysis of law enforcement populations using bioelectrical impedance analysis (BIA). BIA devices operate via measure the resistance and 
reactance of the participant's body tissues relative to a small electrical current emitted by the device, and can vary in cost and practicality (41). There has been some analysis of BIA in law enforcement populations using high-end expensive equipment on employees $(23,24,43)$. For example, Kukić et al. (23) attempted to use different components of body composition (including SMM and FM) to predict performance in 2-minute push-up and sit-up tests, and a 3.2-km run, and a combined fitness test score. Although it is questionable whether fitness should be predicted from body composition, Kukić et al. (23) did find small regression prediction equations for body composition and the combined fitness test score $\left(r^{2}=0.24-0.25\right)$. Kukić et al. (24) found that body fat tended to increase with age in female police officers, which is not unexpected given population trends (16). It should be noted the equipment used in these studies has costs outside the reach of many LEAs in the USA, especially in the current environment of reduced budget allocations (44). Other, more popular BIA devices are small, easy to transport, and inexpensive when testing large groups (41). It would be of benefit to measure the body composition of law enforcement recruits via more practical BIA methods. Furthermore, although previous research has shown relationships between body composition and fitness in incumbent officers $(12,13,42)$, this type of analysis has not been conducted among law enforcement recruits prior to academy.

This information is important to present to LEA staff for several reasons. Firstly, if it is clear that either SMM or FM relates to physical fitness in recruits, this information could be used to set training recommendations for law enforcement recruits prior to and during academy. Secondly, this study could illustrate the potential value of tracking body composition during a law enforcement academy. Accordingly, this study used retrospective data to analyze the relationships between SMM percentage (SMM\%) and FM percentage (FM\%) with physical fitness tests in law 
enforcement recruits from one LEA. With reference to previous research $(12,13,42)$, it was hypothesized that greater SMM\% and lesser FM\% would relate to better fitness test performance.

\section{METHODS}

\section{Experimental Approach to the Problem}

A retrospective analysis of existing data was performed to investigate the potential influence that SMM\% and FM\% may have upon fitness test performance in law enforcement recruits. Partial correlations controlling for sex were used to investigate relationships between SMM\% and FM\% on performance in fitness tests in the recruits. Recruits were stratified into quartiles to create lowto-high SMM\%, and high-to-low FM\%, groups. A one-way multivariate analysis of variance (MANOVA), with sex as a covariate, was used to compare the different SMM\% and FM\% groups. Sex was controlled for in both the correlation and MANOVA analysis as females tend to carry more body fat than males (17), and have lesser performance in law enforcement fitness tests $(5,26,28,31)$.

\section{Subjects}

As stated, a retrospective analysis of data for recruits from four academy classes belonging to one LEA was analyzed. Data from 338 recruits, including 271 males and 67 females, were provided to the researchers and analyzed in this study. The age, height, and body mass of recruits is shown in Table 1. Based on the archival nature of this analysis, the institutional ethics committee approved the use of pre-existing data (HSR-17-18-370). The data were released for analysis via gatekeeper approvals from the LEA. The study conformed to the recommendations of the Declaration of Helsinki (45). 


\section{Procedures}

The data in this study were collected by staff working for one LEA, using procedures established in the literature $(26,27,30,31)$. The staff were all trained by a certified Tactical Strength and Conditioning Facilitator who verified the proficiency of the staff members. All tests were conducted outdoors on concrete or asphalt surfaces at the LEA's training facility on a day scheduled by the LEA staff $(26,30,31)$, and recruits wore their physical training attire (cotton tshirt, shorts, and athletic sneakers). The four training cohorts completed their academy within 2018-19 in southern California where seasonal temperatures remain relatively constant across a year $\left(18^{\circ} \mathrm{C} / 64.4^{\circ} \mathrm{F}-29^{\circ} \mathrm{C} / 84.2^{\circ} \mathrm{F}\right)$. Testing occurred between 0900-1400 (9:00am-2:00pm) depending on recruit availability. Recruits typically did not eat in the 2-3 hours prior to their testing session as they were completing employee-specific documentation. It should be noted that hydration was not controlled for in the recruits, and this could influence the body composition data (7). Further, food consumption was not controlled, although they generally could not eat due to the afore-mentioned administrative responsibilities (26,30). Although this situation is not ideal, and could be controlled for by the investigators due to this being a retrospective study, it was typical of the real-world academy conditions for the recruits $(26,27,30,31)$.

Following the measurement of height, body composition, and grip strength, recruits completed the other fitness tests. Recruits rotated through the fitness tests in small groups of 3-4, except for the 20MSFT which was completed last in groups of 14-16. Recruits were allocated to a testing station before rotating to the next station once all groups were completed. All recruits completed the 20MSFT last. The testing procedures were typical of staff from this LEA, and within numerous published studies $(26,27,30,31)$. 


\section{Body Composition}

Prior to testing, each recruit's age, height, and body mass were recorded. Recruit's removed their shoes to have their height measured using a portable stadiometer (seca, Hamburg, Germany). Body mass, SMM\%, and FM\% was recorded by electronic digital scales, which included bioelectrical impedance analysis (BIA) to estimate body composition (Model HBF-510, Omron Healthcare, Kyoto, Japan). The BIA equipment used in this study has been found to be reliable (intra-class correlation coefficient $\geq 0.95-0.99)$ in college-aged men and women (20,41). Vasold et al. (41) also found high validity when comparing the BIA equipment used in this study to when compared to air displacement plethysmography when measuring fat-free mass (combined males and females $r=0.97$, standard error of estimate $=1.8 \mathrm{~kg}$; males $r=0.94$, standard error of estimate $=1.5 \mathrm{~kg}$; females $r=0.90$, standard error of estimate $=1.3 \mathrm{~kg}$ ). BIA is more cost-effective and practical method for measuring body composition (41), especially for LEAs in the USA where budgetary constraints are a major issue (44). This is especially important when testing large groups with limited tine available for testing. Indeed, funding constraints from the LEA, and time constraints on testing days for the agency, prohibit the use of equipment such as more expensive BIA equipment (e.g. InBody analyzers) or air displacement plethysmography.

Protocol guidelines provided from the manufacture were used to record body composition via BIA (41). The recruit's age, height in $\mathrm{cm}$, and sex were entered into the device, and the recruit also wore no shoes or socks. They then stepped onto the scale with their feet positioned on the foot and heel electrodes. The recruit was then instructed to hold the display unit with both hands until their body mass was displayed on the screen. The display unit also featured electrodes on the handles, and the hands were to be positioned on top of these electrodes. The unit was an example 
of a tetrapolar device, where impedance was measured through the legs, lower trunk only, arms, and upper trunk (6). Once the recruit's feet and hands were positioned on the appropriate electrodes (eight in total) (6), they were to stand upright and extend their arms so they were parallel to the ground. The BIA was completed when the recruit's body mass was displayed again. Proprietary equations from the device provided measurements of body mass, SMM\%, and FM\% (6). The tester scrolled through the data on the display unit and recorded the variables of interest.

\section{Grip Strength}

Grip strength for each hand was measured by a hand grip dynamometer (Takei Scientific Instruments, Japan). Grip strength has been used in a number of different law enforcement studies $(11,14,28,30,33)$, and thus is a valid measure of strength in the context of this research. The equipment and procedures used also present high reliability for men and women (intra-class correlation coefficients $\geq 0.85-0.95)(1,18)$. Recruits kept their testing arm by their side when standing throughout the assessment and squeezed the handle as hard as possible for approximately $2 \mathrm{~s}$, which was monitored by the tester $(14,28,30)$. Two attempts were completed for each hand and recorded to the nearest $\mathrm{kg}$, with the left hand tested first (30). The best score for each hand was summed together to provide the combine grip strength score that was used for analysis.

\section{Vertical Jump (VJ)}

The VJ was measured by a Vertec apparatus (Vertec Scientific Ltd., Aldermaston, UK), which provided an indirect metric for lower-body power $(26,30)$. The recruit initially stood side-on to the Vertec (on the recruit's dominant side), reached upward as high as possible, and fully elevated the shoulder to displace as many vanes as possible, all while keeping their heels on the ground. The 
last vane moved became the zero reference. The recruit then jumped as high as possible, with no preparatory step, and height was recorded from highest vane moved. No restrictions were placed on the range of countermovement during the jump. VJ height was calculated in inches by subtracting the standing reach height from the jump height, before being converted to $\mathrm{cm}$. Each recruit completed two trials, with a recovery time between trials of approximately $60 \mathrm{~s}$, and the best trial was used for analysis.

\section{5-Yard Pursuit Run (75PR)}

The 75PR simulated a foot pursuit (5,30) (Figure 1), and provided a measure of change-ofdirection speed, which can be inclusive of power, acceleration, deceleration, and cutting ability (37). The recruit completed five sprints about a square grid (each side was $12.1 \mathrm{~m}$ ), while completing four, $45^{\circ}$ direction changes zig-zagging across the grid. Recruits also stepped over three 2.44-m long and 0.15-m high barriers that simulated curbs during three of the five sprints. Time was recorded via a stopwatch, from the initiation of movement at the start, until the recruit crossed the finish line. Stopwatch timing was the standard measurement technique for this test $(5,30)$. Two trials were completed with at least two minutes rest between trials, and the fastest trial was analyzed.

\section{***INSERT FIGURE 1 ABOUT HERE***}

\section{Medicine Ball Throw (MBT)}

The MBT was used to indirectly measure upper-body power $(26,30)$. The recruit sat on the ground with their head, shoulders, and lower back against a concrete wall, and projected a 2-kg medicine 
ball (Champion Barbell, Texas, USA) as far as possible using a two-handed chest pass. The ball was lightly dusted with chalk to assist with grip and mark the landing spot. The measurement taken, using a standard tape measure, was the perpendicular distance from the wall to the chalkmarking closest to the wall made by the ball. Two trials were completed, with a recovery time between trials of approximately $60 \mathrm{~s}$, and the best trial was analyzed.

\section{Push-ups}

Upper-body muscular endurance was assessed via a 60-s push-up test. This is a standard test in law enforcement, and the protocol followed established procedures (10,12,25,28,30). A tester placed a fist on the floor directly under the recruit's chest to ensure they descended to an appropriate depth (28). All female recruits were partnered with a female tester. The width of the hands was personal preference for the recruit (23). On the start command, the tester began the stopwatch and the recruit flexed their elbows and lowered themselves until their chests contacted the tester's fist before they extended their elbows to return to the start position. Recruits performed as many push-ups as possible in $60 \mathrm{~s}$ using this technique.

\section{Sit-ups}

Abdominal muscular endurance was assessed via the 60 -s sit-up test $(10,12,25,28,30)$. The recruits laid on their backs with their knees flexed to $90^{\circ}$, heels flat on the ground, and arms crossed over the chest. The feet were held to the ground by a tester who also counted the repetitions. On the start command, recruits raised their shoulders from the ground while keeping their arms crossed over the chest and touched their elbows to their knees. They then descended back down until their 
shoulder blades contacted the ground. Recruits completed as many repetitions as possible using this technique in $60 \mathrm{~s}$.

\section{0-m Multi-Stage Fitness Test (20MSFT)}

The 20MSFT was used to measure aerobic performance and was conducted outdoors on an asphalt surface $(27,30,31)$. Although these may not be the recommended conditions to conduct the 20MSFT, this was the only available space at the LEA's training facility. Recruits were required to run back and forth between two lines 20 -m apart, which were indicated by markers. The speed of running was standardized by pre-recorded auditory cues (i.e. beeps) played from an iPad handheld device (Apple Inc., Cupertino, California) connected via Bluetooth to a portable speaker (ION Block Rocker, Cumberland, Rhode Island). The speaker was located in the center of the running area, and positioned so it would not interfere with the recruits. The test was terminated when the recruit was unable to reach the lines twice in a row in accordance with the auditory cues, or by volitional exhaustion. This test was scored according to the final stage the recruit was able to achieve, and the stage was used to calculate the total number of completed shuttles.

\section{Statistical Analysis}

Statistical analyses were processed using the Statistics Package for Social Sciences (Version 26; IBM Corporation, New York, USA). Normality of the fitness test data for each sex was confirmed by visual analysis of the Q-Q plots (8). To confirm the need to control for sex in the correlation analysis, independent samples t-tests were used to calculate any differences in any of the variables between men and women. Statistical significance was set a priori at $p<0.05$, and descriptive data were presented (mean \pm standard deviation $[\mathrm{SD}]$; 95\% confidence intervals $[\mathrm{CI}]$ ). It was expected 
that sex needed to be controlled in the study analyses as females tend to carry more body fat than males (17), and have lesser performance in typical LEA fitness tests $(5,26,28,31)$. Partial correlations controlling for sex were used to calculate relationships between SMM\% and FM\% with the physical fitness tests. The correlation $(r)$ strength was designated as: an $r$ between 0 to \pm 0.3 was small; \pm 0.31 to \pm 0.49 , moderate; \pm 0.5 to \pm 0.69 , large; \pm 0.7 to \pm 0.89 , very large; and \pm 0.9 to \pm 1 near perfect for relationship prediction $(21)$.

The second part of the analysis was based upon that by Lockie et al. (30). The recruits (males and females were combined) were stratified into quartiles to create low-to-high SMM\% groups, and high-to-low FM\% groups. Although there are inherent sex-based differences in body composition (17), there are no corrections or adjustments made for sex in fitness testing for this agency or the state in which the agency is based (25). The quartiles were based on the sample size of 338 , and cut points were calculated according to the formula: 25 or 50 or $75 / 100 \times(338+1)$. This resulted in four groups: Group 1 (lowest $25 \%$ of the sample for SMM\%, or highest $25 \%$ of the sample for FM\%; i.e. poorest profile for SMM\% or FM\%); Group 2 (second lowest 25\% of the sample for SMM\%, or second highest $25 \%$ of the sample for FM\%); Group 3 (second highest $25 \%$ of the sample for SMM\%, or second lowest $25 \%$ of the sample for FM\%); and Group 4 (highest $25 \%$ of the sample for SMM\%; lowest $25 \%$ of the sample for FM\%; i.e. best profile for SMM\% or FM\%). When SMM\% scores overlapped between quartiles, recruits that had the same score were placed in the lower quartile. When FM\% scores overlapped between quartiles, recruits that had the same score were placed in the higher quartile. This meant that although each group did not have the same number of recruits, there was a clearer delineation between the groups (30). A one-way multivariate analysis of variance (MANOVA), with sex as a covariate, and Bonferroni post hoc adjustment for multiple pairwise comparisons, was used to calculate any differences 12 
between the groups. Statistical significance was set at $p<0.05$. The sex-adjusted descriptive data were presented as mean \pm standard error (SE) and $95 \%$ CI.

\section{RESULTS}

The descriptive data for all recruits combined, males, and females, are shown in Table 1. There were significant differences between the sexes for all variables except age. Females, in general, had a lower SMM\% and greater FM\%, and performed poorer in all fitness tests. This confirmed the need to control for sex in the correlation analysis. The partial correlation data are shown in Table 2. SMM\% correlated with all fitness tests except for the MBT, while FM\% correlated with all except grip strength and the MBT. The strength of all significant relationships with the fitness tests was small. Any significant relationship for SMM\% suggested that a greater SMM\% related to better fitness test performance, while the opposite was true for FM\%

\section{***INSERT TABLE 1 ABOUT HERE*** \\ ***INSERT TABLE 2 ABOUT HERE***}

The sex-adjusted descriptive data for the recruits stratified by SMM\% are shown in Table 3. As would be expected, there were significant $(p<0.001)$ differences between all groups for SMM\% and FM\%. Group 4 had the highest SMM\% and lowest FM\%, with the opposite being true for Group 1. Group 4 was significantly $(p=0.010)$ younger than Group 2. Group 3 was significantly $(p \leq 0.001)$ lighter and had a smaller WC than Groups 1 and 2, while Group 4 was lighter and had a smaller WC than all other groups. Group 2 had a greater WHR than Groups 3 and $4(p=0.001)$. Group 4 had a significantly greater VJ than Groups $1(p=0.026)$ and $3(p=$ 
0.050). Groups $3(p=0.025)$ and $4(p=0.001)$ were significantly faster than Group 2 in the 75PR. Group 4 completed more push-ups than Groups $1(p<0.001)$ and $2(p=0.006)$, while Group 3 completed more push-ups than Group $1(p=0.004)$. Groups 3 and 4 both completed significantly $(p \leq 0.048)$ more sit-up repetitions and 20MSFT shuttles than Groups 1 and 2.

***INSERT TABLE 3 ABOUT HERE***

The sex-adjusted descriptive data for the recruits stratified by FM\% are shown in Table 4. As for the SMM\% groups, there were significant $(p<0.001)$ differences between all groups for SMM\% and FM\%. Group 4 again had the highest SMM\% and lowest FM\%, with the opposite being true for Group 1. Group 4 was lighter than all other groups; Group 3 was lighter than Groups 1 and $2(p \leq 0.001)$. There were significant $(p \leq 0.030)$ differences between all groups for WC, with Group 1 having the highest value, and Group 4 the lowest. Group 4 had a lower WHR than Groups 1 and $2(p<0.001)$, while Group 3 was lower than Group $1(p=0.015)$. Group 4 had a significantly better VJ than Groups $1(p=0.001)$ and $2(p=0.022)$. For the 75PR, Group 4 was faster than Groups $1(p=0.001)$ and $2(p=0.036)$, while Group 3 was faster than Group $1(p=$ 0.006). Group 4 completed more push-up and sit-up repetitions than Groups 1 and $2(p \leq 0.018)$, and Group 3 completed more push-ups and sit-ups than Group $1(p \leq 0.009)$. Regarding the 20MSFT, Group 4 completed more shuttles than all other groups $(p \leq 0.034)$, and Group 3 completed more shuttles than Group $1(p=0.042)$.

***INSERT TABLE 4 ABOUT HERE***

14

This is a non-final version of an article published in final form in:

Lockie, R. G., Carlock, B., Ruvalcaba, T. J., Dulla, J., Orr, R. M., Jay Dawes, J., \& McGuire, M. (2021). Skeletal Muscle Mass and Fat

Mass Relationships With Physical Fitness Test Performance in Law Enforcement Recruits Before Academy. Journal of Strength and Conditioning Research, 35(5), 1287-1295. https://doi.org/10.1519/JSC.0000000000003918 


\section{DISCUSSION}

This study investigated the relationships between SMM\% and FM\% with fitness test performance in law enforcement recruits. This should assist with decisions regarding any modifications for the training completed by recruits, especially if training staff are supposed to monitor body composition as mandated by the state (35). The partial correlation and MANOVA analysis generally showed that greater SMM\%, and lesser FM\%, related to better performance in the fitness tests. This was in support of the study hypotheses, in addition to previous research $(12,13,42)$. It should be acknowledged that any significant relationships between SMM\% and FM\% measured via BIA and fitness test performance were small, and some of the between-group differences could also be related to body size and mass of the recruits (29). Nonetheless, the SMM\% and FM\% results still have practical application. Furthermore, BIA provides a practical and affordable method for measuring body composition in law enforcement recruits. Recruits should attempt to increase SMM\% and decrease FM\% prior to academy, as this will aid them during physical training and fitness testing. Further, LEA staff should attempt to create a training environment that encourages increased SMM\% and healthy FM\%.

Previous research has shown that law enforcement officers with greater SMM (13) and lesser FM $(12,13,42)$ estimated via skinfold measurements tend to perform better in general tests of physical fitness. The results from the current study in law enforcement recruits supported these findings. SMM\% correlated with all fitness tests except the MBT, and the relationships indicated greater SMM\% related to better test performance. FM\% correlated with all fitness tests except grip strength and the MBT, and conversely, greater FM\% related to poorer test performance. It should be noted that the correlations were small for all relationships with the fitness tests. This is because numerous other factors can contribute to fitness test performance as well. For example, linear and 
change-of-direction speed, maximal strength, multidirectional power, and movement technique would influence 75PR performance (37). Performance in the 20MSFT as a measure of aerobic fitness would not just be affected by SMM and FM in the recruits. Aerobic metabolism, highintensity running capabilities, and running technique would also be contributing factors to the 20MSFT (19,31). Nevertheless, the strength of correlations in this study were not dissimilar to that presented by Kukić et al. (23). When correlating variables including different estimates of skeletal muscle and fat mass measured via BIA, to 2-minute push-up and sit-up tests and a 3.2-km run, significant correlations ranged from $\pm 0.168-0.436$. Displaying these correlation strengths was somewhat problematic in the Kukić et al. (23) study given they were attempting to predict fitness test performance via body composition, which led to small regression equations $\left(r^{2}=0.24-0.25\right)$. Furthermore, the partial correlation data in this study were supported by the MANOVA analysis.

When considering the SMM\% and FM\% groups, there were clear differences in fitness between Groups 3 and 4 (the best profile for either SMM\% or FM\%) compared to Group 1, who either had the lowest SMM\% or greatest FM\%. Specifically for the SMM\% groups, Group 4 had a 14\% higher VJ compared to Group 1, and a 9\% higher VJ than Group 3. Groups 3 and 4 were 2$3 \%$ faster in the 75PR compared to Group 1. For the push-up test, Groups 3 and 4 completed 25\% and 33\% more repetitions than Group 1, respectively. Group 4 completed 15\% more push-up repetitions than Group 2. Groups 3 and 4 completed 14-23\% more sit-up repetitions, and 13-36\% more MSFT shuttles, than Groups 1 and 2. With regards to the FM\% groups, Group 4 had a 13$16 \%$ higher VJ compared to Groups 1 and 2. Groups 3 and 4 were 3-4\% faster in the 75PR relative to Group 1; Group 4 was 3\% faster than Group 2. Groups 3 and 4 completed 20\% and 24\% more push-up repetitions than Group 1, respectively. Group 4 completed 15\% more push-up repetitions than Group 2. Groups 3 and 4 completed 17-20\% more sit-up repetitions than Groups 1 and 2, and

16

This is a non-final version of an article published in final form in:

Lockie, R. G., Carlock, B., Ruvalcaba, T. J., Dulla, J., Orr, R. M., Jay Dawes, J., \& McGuire, M. (2021). Skeletal Muscle Mass and Fat Mass Relationships With Physical Fitness Test Performance in Law Enforcement Recruits Before Academy. Journal of Strength and Conditioning Research, 35(5), 1287-1295. https://doi.org/10.1519/JSC.0000000000003918 
Group 4 completed 14\% more repetitions than Group 2. Lastly, Group 4 completed 13-32\% more MSFT shuttles than all other groups; Group 2 completed 17\% more shuttles than Group 1.

It should be noted that not only body composition, but body size and mass could be contributing to these results. Groups 3 and 4 tended to be the lightest groups, whether differentiated by SMM\% or FM\%. Lockie et al. (29) documented that the mass of civilian males and females impacted the performance of a $123-\mathrm{kg}$ casualty drag, in that heavier individuals could perform this task faster. The results were linked to factors such as greater absolute strength and force generation capabilities in heavier individuals. Nonetheless, Lockie et al. (29) still noted the importance of developing strength and muscle mass in smaller individuals, given that body mass could always be a limiting factor in a task such as a casualty drag. This could be extrapolated to the fitness test data from this study. In conjunction with the significant correlations between SMM\% or FM\% and most fitness tests, there were differences in these variables between the 4 groups differentiated by either SMM\% or FM\%. As a result, SMM\% or FM\% results from this study have practical application, in that recruits should be encouraged to develop SMM and reduce FM prior to their academy training.

There are several reasons for this. As noted, the cumulative effect of poor performance in fitness training could negatively impact any adaptations experienced by a law enforcement recruit (15). If a law enforcement recruit's body composition negatively impacts their physical fitness, this could also increase their chances for separation (i.e. they do not complete academy training) $(15,27)$ and injury (38). It should be noted that specific recommendations regarding how much SMM and FM a recruit should have cannot be provided from the results of this study, and would not be appropriate as this needs to be done by each agency following specific analysis of how this could actually influence job-specific performance. Nonetheless, LEA staff should ideally provide 
some recommendations and guidelines for law enforcement recruits to improve their SMM and FM profile prior to academy training. This is because it could benefit their fitness, which in turn could put them in a better position to complete the physical training requirements of academy and successfully graduate $(15,27,38)$.

Grip strength was not significantly different between the groups quartile split by either SMM\% or FM\%. The MBT did not correlate with either SMM\% or FM\%, and was not significantly different between the SMM\% or FM\% groups. Grip strength is a practical strength measure that is easily reproducible across individuals of different sex, age, and fitness background (32), but only requires isometric force output from each hand (11,14,28,30,33). The MBT provides an indirect measure of upper-body power $(26,30)$, although the projection of a 2-kg ball may not require high-upper-body force output relative to other upper-body tests. The required force output for upper-body pushing exercises such as the bench press increases with a greater load (9). Furthermore, body size (and by extension, muscle mass) can be an influencing factor in maximal strength tests (22). As a law enforcement-specific example, Dawes et al. (13) found a significant relationship between the one-repetition maximum bench press and lean body mass in $\mathrm{kg}$ estimated via skinfold measurements (absolute $r=0.781$; relative $r=0.392$ ). The MBT may not require a high force output, and may not be as affected by the body size of recruits as they are seated and do not need to move their mass. This could have led to the lack of significant results found in this study. Nonetheless, it would be expected that with appropriate whole-body resistance and metabolic training, there should be favorable changes in the body composition of the upper-body (e.g. increased SMM) (10,40). This is important for recruits, as greater upper-body SMM could be beneficial to law enforcement specific-tasks such as suspect restraint, pushing, and striking (13). 
Given the relationships between SMM\% and FM\% with physical fitness, there could be value in tracking the body composition of recruits during the academy training period. This is potentially important, as academy training involves high psychological (4) and physiological $(10,34)$ stress for the recruits. Furthermore, academy training takes place over a period of approximately 6 months $(10,25)$, so this is an extended period of time for recruits to be experiencing high stress. In athletic populations, the rigors of a competitive season can lead to unfavorable changes in body composition. For example, after an approximate 6-month season, male and female competitive cyclists experienced reduced SMM and increased FM (2). Collegiate female softball players experienced a significant decrease in lean body mass from the midseason to postseason period, which was likely influenced by a high training volume mixed with competition (36). Although this research is from athletic populations, this research is applicable as previous studies of law enforcement populations and body composition have typically been crosssectional in nature $(12,13,23,24,42,43)$. Given both the psychological and physical stress associated with academy training, monitoring how body composition could fluctuate during academy could be important for LEA staff. Duty of care is an important consideration for LEA staff when hiring and training their recruits (15). The use of a simple body composition assessment such as BIA could be used as a first step in monitoring impacts of academy training on law enforcement recruits.

Nonetheless, LEA staff need to make appropriate decisions on the equipment to use to monitor BIA. BIA equipment can range from foot placement only, to hand and foot placement $(6,20,23,24,41,43)$. As previously noted, Vasold et al. (41) stated the BIA equipment from this research provided acceptable reliability and validity (relative to air displacement plethysmography) for measuring body composition in adult men and women. Furthermore, the 
price point for the analyzer used in the current study is much lower $(\sim 70)$ than that used in other studies (upwards of $\$ 5000)(23,24,43)$. Cost of equipment is a serious consideration for LEAs, especially in the current social environment (44). Given the results of this study documented relationships between SMM\% and FM\% and fitness test performance in law enforcement recruits, and previous research has shown this equipment is reliable and valid (41), this would add support to LEA staff using this affordable option to track body composition in their recruit classes.

There are limitations to with the use of BIA to measure SMM\% and FM\%, and as such these data should be interpreted with this in mind (7). Nonetheless, this option is more likely to be used by LEAs across the USA then other more expensive and time-consuming procedures $(23,24,43)$, especially with large recruit classes. In addition, previous research recommended further investigation for the use of BIA in law enforcement populations (30), which this study has done and shown potential value for the SMM\% and FM\% data recorded via BIA. Nonetheless, it would be of benefit to compare SMM and FM data recorded from different BIA analyzers specific to law enforcement recruits. As stated, hydration was not controlled for, which can influence body composition data recorded from BIA equipment (7). Food consumption was not controlled before testing, although recruits generally did not get the opportunity to eat because they were completing paperwork (26,30,31). Future studies should attempt to control food and fluid intake (and time of day testing for follow-up analyses) of recruits prior to BIA testing $(23,24,43)$. However, the authors do note that this is not always possible in the law enforcement recruit training environment.

\section{PRACTICAL APPLICATIONS}

The measurement of body composition via BIA could provide practical data that may assist with occupational health and safety of law enforcement recruits. Law enforcement recruits should 
attempt to increase SMM and decrease FM prior to academy such that they can perform better in fitness testing and training, as this should better optimize their chances of graduation. As a duty of care to recruits, LEA staff could also use BIA to monitor the body composition of recruits during academy to measure how they are tolerating the rigors of training.

\section{ACKNOWLEDGEMENTS}

This research project received no external financial assistance. None of the authors have any conflict of interest. The authors would like to thank the training instructors for facilitating this research, and the California State University, Fullerton tactical research team for collating the data.

\section{REFERENCES}

1. Amaral, JF, Mancini, M, and Novo Júnior, JM. Comparison of three hand dynamometers in relation to the accuracy and precision of the measurements. Braz J Phys Ther 16: 216$224,2012$.

2. Baker, BS and Reiser, RF. Longitudinal assessment of bone mineral density and body composition in competitive cyclists. J Strength Cond Res 31: 2969-2976, 2017.

3. Beck, AQ, Clasey, JL, Yates, JW, et al. Relationship of physical fitness measures vs. occupational physical ability in campus law enforcement officers. J Strength Cond Res 29: 2340-2350, 2015.

4. Berg, BL. First day at the police academy: Stress-Reaction-Training as a screening-out technique. J Contemp Crim Justice 6: 89-105, 1990.

21

This is a non-final version of an article published in final form in:

Lockie, R. G., Carlock, B., Ruvalcaba, T. J., Dulla, J., Orr, R. M., Jay Dawes, J., \& McGuire, M. (2021). Skeletal Muscle Mass and Fat

Mass Relationships With Physical Fitness Test Performance in Law Enforcement Recruits Before Academy. Journal of Strength and Conditioning Research, 35(5), 1287-1295. https://doi.org/10.1519/JSC.0000000000003918 
5. Bloodgood, AM, Dawes, JJ, Orr, RM, et al. Effects of sex and age on physical testing performance for law enforcement agency candidates: Implications for academy training. $J$ Strength Cond Res: doi:10.1519/jsc.0000000000003207, in press.

6. Bosy-Westphal, A, Later, W, Hitze, B, et al. Accuracy of bioelectrical impedance consumer devices for measurement of body composition in comparison to whole body magnetic resonance imaging and dual X-ray absorptiometry. Obes Facts 1: 319-324, 2008.

7. Burns, RD, Fu, Y, and Constantino, N. Measurement agreement in percent body fat estimates among laboratory and field assessments in college students: Use of equivalence testing. PLOS One 14: e0214029, 2019.

8. Callaghan, SJ, Lockie, RG, Andrews, WA, Chipchase, RF, and Nimphius, S. The relationship between inertial measurement unit-derived 'force signatures' and ground reaction forces during cricket pace bowling. Sport Biomech 19: 307-321, 2020.

9. Clark, RA, Bryant, AL, and Humphries, B. A comparison of force curve profiles between the bench press and ballistic bench throws. J Strength Cond Res 22: 1755-1759, 2008.

10. Cocke, C, Dawes, J, and Orr, RM. The use of 2 conditioning programs and the fitness characteristics of police academy cadets. J Athl Train 51: 887-896, 2016.

11. Copay, AG and Charles, MT. The influence of grip strength on handgun marksmanship in basic law enforcement training. Policing: Intl J Police Strat \& Mgmt 24: 32-39, 2001.

12. Dawes, JJ, Orr, RM, Elder, CL, and Rockwell, C. Association between body fatness and measures of muscular endurance among part-time SWAT officers. J Aust Strength Cond 22: 33-37, 2014. 
13. Dawes, JJ, Orr, RM, Siekaniec, CL, Vanderwoude, AA, and Pope, R. Associations between anthropometric characteristics and physical performance in male law enforcement officers: A retrospective cohort study. Ann Occup Environ Med 28: 26, 2016.

14. Dawes, JJ, Orr, RM, Flores, RR, et al. A physical fitness profile of state highway patrol officers by gender and age. Ann Occup Environ Med 29: 16, 2017.

15. Dawes, JJ, Lockie, RG, Orr, RM, Kornhauser, C, and Holmes, RJ. Initial fitness testing scores as a predictor of police academy graduation. J Aust Strength Cond 27: 30-37, 2019.

16. Fryar, CD, Gu, Q, Ogden, CL, and Flegal, KM. Anthropometric reference data for children and adults: United States, 2011-2014. Vital Health Stat 3: 1-46, 2016.

17. Gallagher, D, Heymsfield, SB, Heo, M, et al. Healthy percentage body fat ranges: an approach for developing guidelines based on body mass index. Am J Clin Nutr 72: 694$701,2000$.

18. Gatt, I, Smith-Moore, S, Steggles, C, and Loosemore, M. The Takei handheld dynamometer: An effective clinical outcome measure tool for hand and wrist function in boxing. Hand 13: 319-324, 2018.

19. Green, MS, Esco, MR, Martin, TD, et al. Crossvalidation of two 20-m shuttle-run tests for predicting VO2max in female collegiate soccer players. J Strength Cond Res 27: 1520$1528,2013$.

20. Hart, P. Test-retest stability of four common body composition assessments in college $\begin{array}{lllllll}\text { students. } & J & \text { Phys } & \text { Fit } & \text { Med }\end{array}$ https://doi.org/10.19080/JPFMTS.2017.01.555561, 2017.

21. Hopkins, W.G. A scale of magnitude for effect statistics, 2013. Available from: www.sportsci.org/resource/stats/index.html. Retrieved January 9, 2016. 
22. Jaric, S, Mirkov, D, and Markovic, G. Normalizing physical performance tests for body size: A proposal for standardization. J Strength Cond Res 19: 467-474, 2005.

23. Kukić, F, Dopsaj, M, Dawes, J, Orr, R, and Čvorović, A. Use of human body morphology as an indication of physical fitness: Implications for police officers. Int J Morphol 36: 1407-1412, 2018.

24. Kukić, F, Scekic, A, Koropanovski, N, et al. Age-related body composition differences in female police officers. Int J Morphol 37: 302-307, 2019.

25. Lockie, RG, Dawes, JJ, Balfany, K, et al. Physical fitness characteristics that relate to Work Sample Test Battery performance in law enforcement recruits. Int J Environ Res Public Health 15: 2477, 2018.

26. Lockie, RG, Dawes, JJ, Orr, RM, et al. An analysis of the effects of sex and age on upperand lower-body power for law enforcement agency recruits prior to academy training. $J$ Strength Cond Res 32: 1968-1974, 2018.

27. Lockie, RG, Balfany, K, Bloodgood, AM, et al. The influence of physical fitness on reasons for academy separation in law enforcement recruits. Int J Environ Res Public Health 16: $372,2019$.

28. Lockie, RG, Orr, RM, Stierli, M, et al. The physical characteristics by sex and age for custody assistants from a law enforcement agency. J Strength Cond Res 33: 2223-2232, 2019.

29. Lockie, RG, Moreno, MR, Ducheny, SC, et al. Analyzing the training load demands, and influence of sex and body mass, on the tactical task of a casualty drag via surface electromyography wearable technology. Int J Exerc Sci 13: 1012-1027, 2020. 
30. Lockie, RG, Ruvalcaba, TR, Stierli, M, et al. Waist circumference and waist-to-hip ratio in law enforcement agency recruits: Relationship to performance in physical fitness tests. J Strength Cond Res 34: 1666-1675, 2020.

31. Lockie, RG, Dawes, JJ, Moreno, MR, et al. Relationship between the 20-m multistage fitness test and 2.4-km run in law enforcement recruits. J Strength Cond Res: doi:10.1519/jsc.0000000000003217, in press.

32. Massy-Westropp, NM, Gill, TK, Taylor, AW, Bohannon, RW, and Hill, CL. Hand grip gtrength: Age and gender stratified normative data in a population-based study. BMC Research Notes 4: 127, 2011.

33. Orr, R, Pope, R, Stierli, M, and Hinton, B. Grip strength and its relationship to police recruit task performance and injury risk: A retrospective cohort study. Int J Environ Res Public Health 14: 941, 2017.

34. Orr, RM, Ford, K, and Stierli, M. Implementation of an ability-based training program in police force recruits. J Strength Cond Res 30: 2781-2787, 2016.

35. Peace Officer Standards and Training. Training and Testing: Specifications for Learning Domain \#32 Lifetime Fitness, 2013. Available from: https://post.ca.gov/post_docs/training/trainingspecs/LD32.doc. Accessed July 18, 2019.

36. Peart, A, Wadsworth, D, Washington, J, and Oliver, G. Body composition assessment in female National Collegiate Athletic Association Division I softball athletes as a function of playing position across a multiyear time frame. J Strength Cond Res 33: 3049-3055, 2019. 
37. Post, BK, Dawes, JJ, and Lockie, RG. Relationships between tests of strength, power, and speed and the 75-yard pursuit run. $J$ Strength Cond Res: doi:10.1519/jsc.0000000000003398, in press.

38. Tomes, C, Orr, RM, and Pope, R. The impact of body armor on physical performance of law enforcement personnel: A systematic review. Ann Occup Environ Med 29: 14, 2017.

39. Tomes, CD, Sawyer, S, Orr, R, and Schram, B. Ability of fitness testing to predict injury risk during initial tactical training: A systematic review and meta-analysis. Inj Prev 26: 67$81,2020$.

40. Vargas, S, Petro, JL, Romance, R, et al. Comparison of changes in lean body mass with a strength- versus muscle endurance-based resistance training program. Eur J Appl Physiol 119: 933-940, 2019.

41. Vasold, KL, Parks, AC, Phelan, DML, Pontifex, MB, and Pivarnik, JM. Reliability and validity of commercially available low-cost bioelectrical impedance analysis. Int J Sport Nutr Exerc Metab 29: 406-410, 2019.

42. Violanti, JM, Ma, CC, Fekedulegn, D, et al. Associations between body fat percentage and fitness among police officers: A statewide study. SH@W 8: 36-41, 2017.

43. Vuković, M, Kukić, F, Čvorović, A, et al. Relations between frequency and volume of leisure-time physical activity and body composition in police officers. Res $Q$ Exerc Sport 91: 47-54, 2020.

44. Weichselbaum, S and Lewis, N. Support For defunding the police department is growing. Here's why it's not a silver bullet, 2020. Available from https://www.themarshallproject.org/2020/06/09/support-for-defunding-the-policedepartment-is-growing-here-s-why-it-s-not-a-silver-bullet. Accessed August 13, 2020. 
45. World Medical Association. World Medical Association Declaration of Helsinki. Recommendations guiding physicians in biomedical research involving human subjects.

JAMA 277: 925-926, 1997.

\section{FIGURE LEGEND}

Figure 1: 75PR dimensions (A) and the running direction (numbered in order; B). The barriers were $2.44 \mathrm{~m}$ long and $0.15 \mathrm{~m}$ high. 
Table 1: Descriptive data (mean \pm SD; 95\% CI) for all combined, males, and females, in the anthropometric and physical fitness tests for law enforcement recruits.

\begin{tabular}{|c|c|c|c|}
\hline & All $(\mathrm{N}=338)$ & Males $(n=271)$ & Females $(n=67)$ \\
\hline Age (years) & $27.02 \pm 6.02(26.38-27.67)$ & $27.11 \pm 6.25(26.37-27.86)$ & $26.66 \pm 5.01(25.44-27.88)$ \\
\hline Height (m) & $1.71 \pm 0.09(1.70-1.72)$ & $1.74 \pm 0.08(1.73-1.75)$ & $1.60 \pm 0.06 *(1.59-1.62)$ \\
\hline Body Mass (kg) & $80.19 \pm 14.48(78.64-81.74)$ & $84.03 \pm 13.07(82.46-85.59)$ & $64.67 \pm 8.17 *(62.68-66.66)$ \\
\hline $\operatorname{SMM}(\%)$ & $34.76 \pm 5.76(34.14-35.37)$ & $36.44 \pm 4.77(35.86-37.01)$ & $27.96 \pm 4.19 *(26.94-28.98)$ \\
\hline $\mathrm{FM}(\%)$ & $27.20 \pm 7.17(26.43-27.97)$ & $25.32 \pm 6.13(24.59-26.05)$ & $34.79 \pm 6.01 *(33.32-36.25)$ \\
\hline Grip Strength (kg) & $94.07 \pm 23.47(91.56-96.58)$ & $101.00 \pm 20.19(98.59-103.42)$ & $66.03 \pm 12.16 *(63.06-69.00)$ \\
\hline $\mathrm{VJ}(\mathrm{cm})$ & $54.03 \pm 13.82(52.55-55.50)$ & $57.58 \pm 12.69(56.07-59.11)$ & $39.62 \pm 7.33 *(37.83-41.40)$ \\
\hline $75 \mathrm{PR}(\mathrm{s})$ & $17.07 \pm 1.22(16.94-17.20)$ & $16.77 \pm 1.00(16.66-16.89)$ & $18.28 \pm 1.30 *(17.96-18.60)$ \\
\hline $\operatorname{MBT}(\mathrm{m})$ & $6.03 \pm 1.37(5.89-6.18)$ & $6.48 \pm 1.12(6.34-6.61)$ & $4.25 \pm 0.56^{*}(4.11-4.38)$ \\
\hline Push-ups (no.) & $42.53 \pm 15.64(40.85-44.20)$ & $46.92 \pm 13.59(45.29-48.54)$ & $24.78 \pm 9.77 *(22.39-27.16)$ \\
\hline Sit-ups (no.) & $35.80 \pm 10.29(34.70-36.90)$ & $36.56 \pm 8.93(35.49-37.63)$ & $32.72 \pm 14.20 *(29.25-36.18)$ \\
\hline 20MSFT Shuttles & $53.16 \pm 17.42(51.30-55.03)$ & $54.79 \pm 17.77(52.66-56.91)$ & $46.58 \pm 14.28 *(43.10-50.06)$ \\
\hline
\end{tabular}

* Significantly $(p<0.01)$ different from the male recruits. 
Table 2: Descriptive data (mean \pm SD) for all combined, males, and females, in the anthropometric and physical fitness tests for law enforcement recruits.

\begin{tabular}{|c|c|c|c|}
\hline & & SMM\% & FM\% \\
\hline \multirow[b]{2}{*}{ Grip Strength } & $r$ & 0.107 & -0.105 \\
\hline & $p$ & $0.049 *$ & 0.053 \\
\hline \multirow{2}{*}{ VJ } & $r$ & $0.160 *$ & $-0.170 *$ \\
\hline & $p$ & 0.003 & 0.002 \\
\hline \multirow{2}{*}{$75 \mathrm{PR}$} & $r$ & $-0.208^{*}$ & $0.220 *$ \\
\hline & $p$ & $<0.001$ & $<0.001$ \\
\hline \multirow{2}{*}{ MBT } & $r$ & 0.027 & 0.033 \\
\hline & $p$ & 0.625 & 0.551 \\
\hline \multirow[b]{2}{*}{ Push-ups } & $r$ & $0.211^{*}$ & $-0.232 *$ \\
\hline & $p$ & $<0.001$ & $<0.001$ \\
\hline \multirow{2}{*}{ Sit-ups } & $r$ & $0.205^{*}$ & $-0.218^{*}$ \\
\hline & $p$ & $<0.001$ & $<0.001$ \\
\hline \multirow{2}{*}{ 20MSFT } & $r$ & $0.271 *$ & $-0.293^{*}$ \\
\hline & $p$ & $<0.001$ & $<0.001$ \\
\hline
\end{tabular}

* Significant $(p<0.05)$ relationship between the two variables. 
Table 3: Descriptive data (mean \pm SE; 95\% CI) for age, anthropometry (height, body mass, SMM\%, FM\%, WC, and WHR), and the physical fitness tests for recruits split into quartiles based on SMM\%.

\begin{tabular}{|c|c|c|c|c|}
\hline & Group $1(n=86)$ & Group $2(n=87)$ & Group $3(n=84)$ & Group $4(n=81)$ \\
\hline & Lowest $25 \%$ & $2^{\text {nd }} 25 \%$ & $3^{\text {rd }} 25 \%$ & Highest $25 \%$ \\
\hline Age (years) & $27.48 \pm 0.90(25.72-29.25)$ & $28.43 \pm 0.67(27.11-29.75)$ & $26.56 \pm 0.69(25.22-27.91)$ & $25.50 \pm 0.70 \S(24.13-26.88)$ \\
\hline Height (m) & $1.71 \pm 1.15(1.69-1.73)$ & $1.72 \pm 0.09(1.70-1.74)$ & $1.71 \pm 0.88(1.69-1.72)$ & $1.72 \pm 0.90(1.70-1.73)$ \\
\hline Body Mass (kg) & $85.98 \pm 1.61(82.80-89.15)$ & $86.31 \pm 1.20(83.94-88.68)$ & $77.46 \pm 1.23 * \S(75.04-79.88)$ & $70.31 \pm 1.26 * \S \phi(67.83-72.78)$ \\
\hline SMM\% & $26.91 \pm 0.39(26.14-27.68)$ & $34.18 \pm 0.29 *(33.60-34.75)$ & $37.20 \pm 0.29 * \S(36.61-37.78)$ & $41.17 \pm 0.31 * \S \phi(40.57-41.77)$ \\
\hline FM\% & $35.35 \pm 0.53(34.31-36.39)$ & $29.43 \pm 0.39 *(28.66-30.20)$ & $25.13 \pm 0.40 * \S(24.34-25.92)$ & $18.29 \pm 0.41 * \S \phi(17.48-19.09)$ \\
\hline Grip Strength (kg) & $94.93 \pm 2.85(89.32-100.54)$ & $92.10 \pm 2.13(87.91-96.28)$ & $93.70 \pm 2.17(89.42-97.98)$ & $96.67 \pm 2.22(91.29-100.04)$ \\
\hline $\mathrm{VJ}(\mathrm{cm})$ & $51.06 \pm 1.76(47.60-54.53)$ & $53.81 \pm 1.31(51.22-56.39)$ & $53.31 \pm 1.34(50.67-55.95)$ & $58.14 \pm 1.37 * \phi(55.44-60.84)$ \\
\hline $75 \mathrm{PR}(\mathrm{s})$ & $17.24 \pm 0.16(16.93-17.55)$ & $17.37 \pm 0.12(17.14-17.60)$ & $16.91 \pm 0.12 \S(16.67-17.14)$ & $16.75 \pm 0.12 \S(16.51-16.99)$ \\
\hline $\operatorname{MBT}(\mathrm{m})$ & $6.06 \pm 0.16(5.76-6.37)$ & $6.19 \pm 0.12(5.96-6.42)$ & $5.97 \pm 0.12(5.73-6.20)$ & $5.90 \pm 0.12(6.67-6.14)$ \\
\hline Push-ups (no.) & $36.04 \pm 1.89(32.32-39.75)$ & $41.51 \pm 1.41(38.74-44.29)$ & $45.02 \pm 1.44 *(42.19-47.85)$ & $47.92 \pm 1.47 * \S(45.02-50.82)$ \\
\hline Sit-ups (no.) & $32.19 \pm 1.49(29.26-35.12)$ & $33.51 \pm 1.11(31.32-35.69)$ & $38.21 \pm 1.14 * \S(35.97-40.44)$ & $39.59 \pm 1.16 * \S(37.30-41.87)$ \\
\hline 20MSFT Shuttles & $45.29 \pm 2.47(40.42-50.16)$ & $49.79 \pm 1.85(46.16-53.42)$ & $56.49 \pm 1.89 * \S(52.78-60.20)$ & $61.69 \pm 1.93 * \S(57.89-65.48)$ \\
\hline
\end{tabular}

* Significantly $(p<0.05)$ different from the Lowest $25 \%$ group.

$\S$ Significantly $(p<0.05)$ different from the $2^{\text {nd }} 25 \%$ group.

$\phi$ Significantly $(p<0.05)$ different from the $3^{\text {rd }} 25 \%$ group. 
Table 4: Descriptive data (mean \pm SE; 95\% CI) for age, anthropometry (height, body mass, SMM\%, FM\%, WC, and WHR), and the physical fitness tests for recruits split into quartiles based on FM\%.

\begin{tabular}{|c|c|c|c|c|}
\hline & Group $1(\mathrm{n}=87)$ & Group $2(\mathrm{n}=87)$ & Group $3(n=85)$ & Group $4(n=79)$ \\
\hline & Highest $25 \%$ & $2^{\text {nd }} 25 \%$ & $3^{\text {rd }} 25 \%$ & Lowest $25 \%$ \\
\hline Age (years) & $27.20 \pm 0.73(25.77-28.63)$ & $27.29 \pm 0.65(26.01-28.57)$ & $27.29 \pm 0.67(25.98-28.60)$ & $26.25 \pm 0.70(24.87-27.63)$ \\
\hline Height (m) & $1.70 \pm 0.91(1.68-1.72)$ & $1.72 \pm 0.82(1.70-1.73)$ & $1.71 \pm 0.84(1.69-1.73)$ & $1.73 \pm 0.88(1.71-1.75)$ \\
\hline Body Mass (kg) & $87.51 \pm 1.31(84.92-90.09)$ & $83.89 \pm 1.17(81.59-86.20)$ & $77.58 \pm 1.21 * \S(75.20-79.95)$ & $70.86 \pm 1.27 * \S \phi(68.36-73.36)$ \\
\hline SMM\% & $29.56 \pm 0.38(28.81-30.31)$ & $33.63 \pm 0.34 *(32.96-34.30)$ & $36.03 \pm 0.35^{*} \S(35.34-36.72)$ & $40.34 \pm 0.37 * \S \phi(39.61-41.07)$ \\
\hline FM\% & $35.50 \pm 0.31(34.89-36.12)$ & $29.22 \pm 0.28 *(28.67-29.77)$ & $25.00 \pm 0.29 * \S(24.44-25.56)$ & $18.19 \pm 0.30 * \S \phi(17.59-18.78)$ \\
\hline Grip Strength (kg) & $92.13 \pm 2.26(87.68-96.58)$ & $91.33 \pm 2.02(87.35-95.31)$ & $95.14 \pm 2.08(91.06-99.23)$ & $98.08 \pm 2.19(93.77-102.38)$ \\
\hline $\mathrm{VJ}(\mathrm{cm})$ & $50.74 \pm 1.40(47.99-53.48)$ & $53.30 \pm 1.25(50.85-55.76)$ & $53.85 \pm 1.28(51.33-56.37)$ & $58.63 \pm 1.35 * \S(55.97-61.29)$ \\
\hline $75 \mathrm{PR}(\mathrm{s})$ & $17.46 \pm 0.13(17.21-17.71)$ & $17.19 \pm 0.11(16.97-17.41)$ & $16.88 \pm 0.12 *(16.65-17.10)$ & $16.74 \pm 0.12 * \S(16.50-16.97)$ \\
\hline $\operatorname{MBT}(\mathrm{m})$ & $6.06 \pm 0.13(5.81-6.31)$ & $6.08 \pm 0.11(5.86-6.30)$ & $6.00 \pm 0.12(5.77-6.22)$ & $6.00 \pm 0.12(5.76-6.24)$ \\
\hline Push-ups (no.) & $37.75 \pm 1.51(34.77-40.73)$ & $40.77 \pm 1.35(38.11-43.43)$ & $45.25 \pm 1.39 *(42.52-47.99)$ & $46.79 \pm 1.47 * \S(43.91-49.67)$ \\
\hline Sit-ups (no.) & $32.49 \pm 1.20(30.13-34.85)$ & $34.22 \pm 1.07(32.11-36.33)$ & $37.90 \pm 1.10 *(35.74-40.06)$ & $38.90 \pm 1.16 * \S(35.74-40.06)$ \\
\hline 20MSFT Shuttles & $46.11 \pm 1.99(42.19-50.03)$ & $52.56 \pm 1.78(49.06-56.07)$ & $53.74 \pm 1.83 *(50.15-57.34)$ & $60.96 \pm 1.93 * \S \phi(57.17-64.76)$ \\
\hline
\end{tabular}

* Significantly $(p<0.05)$ different from the Lowest $25 \%$ group.

$\S$ Significantly $(p<0.05)$ different from the $2^{\text {nd }} 25 \%$ group.

$\phi$ Significantly $(p<0.05)$ different from the $3^{\text {rd }} 25 \%$ group. 